Author Accepted Version. Final version published as: Temple, J. B., \& McDonald, P. F. (2018). Australian migration propensities by visa class: an analysis of linked administrative data. Journal of Population Research, 35(4), 399-416.

\title{
Australian Migration Propensities by Visa Class: An Analysis of Linked Administrative Data Abstract
}

Following a number of difficulties measuring net overseas migration (NOM), since 2006 the Australian Bureau of Statistics (ABS) has defined a usual resident of Australia as a person who spends at least 12 months of any given 16-month period in Australia. This is ascertained through matching of individual records for persons moving across Australia's borders, including their Arrival and Departure Cards, their passport movements and their visa grants. The total number of persons counted into the population through arrival in a given quarter is termed NOM Arrivals. The total number of persons counted out of the population through departure in a given quarter is termed NOM Departures. The net of the two numbers is NOM or Net Overseas Migration for the quarter. In the late 2000's the data capturing NOM movements was held by the ABS and the data collected on visa grants was administered by the then Department of Immigration and Citizenship. In this paper, we examine the utility of these now linked administrative data sets in improving our knowledge about the timing and level of NOM propensities, or probabilities of 'NOM tagging' in the Australian migration system. Specifically, we present findings on the estimated event history of NOMing in and NOMing out of Australia using 22 aggregate visa types. These aggregate visa types are defined broadly containing categories such as business skills, employer sponsored, general skilled migration, working holiday makers, students and special humanitarian programme types. Implications of our findings with respect to improving Australian migration forecasting and further data linkages are discussed.

Keywords: International Migration, Visa Class, Administrative Data. 


\section{Australian Migration Propensities by Visa Class:}

\section{An Analysis of Linked Administrative Data}

\section{Introduction}

Australia is a country with a high rate of international migration. The level of this migration has major implications for a wide range of planning issues, even in the shortterm. The headline statistic for migration in Australia is the annual level of Net Overseas Migration (NOM). Hence, there is a policy benefit in having accurate shortterm estimates of the future level of NOM. In 2009, the authors of this paper were approached by the then Minister for Immigration and Citizenship to assist his department in developing a methodology to estimate short-term futures for NOM. As persons other than Australian citizens entering Australia must first obtain an entry visa of some type before they enter Australia, we suggested that individuals granted a visa could be traced across time to see whether they actually entered Australia and whether they stayed sufficiently long to be counted into the Australian population by the Australian Bureau of Statistics (ABS) through being included in $\mathrm{NOM}^{1}$. This paper details the administrative data and some of the measures that we developed. The immigration department subsequently made additions to our approach and the results are now published on a regular basis (see, a recent example, DIBP 2016). These data are unique in an international context, as many other countries that are also significant recipients of immigrants (e.g. Canada) don't collect comparable data on border crossings (particularly departures).

\footnotetext{
${ }^{1}$ While New Zealand citizens have an automatic right of entry to Australia and residence in Australia, they are still granted a visa.
} 
Each year, there are over 30 million movements across Australian borders (ABS, 2013) but the level of net overseas migration used to estimate the resident population of Australia is small in comparison. The levels of net overseas migration to Australia (NOM) from 1980 to 2016 are shown in Figure 1. From 1980 to 2005, levels of NOM fluctuated considerably around an average of about 100,000 but, from 2006 onwards, NOM rose to a new threshold, averaging around 200,000 with a distinct peak of 316,000 in 2008. These trends are potentially affected by two changes to the definition of NOM that were made by the Australian Bureau of Statistics in 1983 and 2006 (described below). Changes in NOM over this period were also driven by major changes in Australian immigration policy and other factors such as strength in the economy(McDonald 2015).

\section{[FIGURE 1]}

In this study, we describe the merging of two detailed administrative data sets to understand the timing and propensity of persons entering or leaving Australia being counted into or out of the Australian population. The total number of persons counted into the population through arrival in a given quarter is termed NOM Arrivals. The total number of persons counted out of the population through departure in a given quarter is termed NOM Departures. The net of the two numbers is NOM or Net Overseas Migration for the quarter. In the late 2000's the data capturing NOM movements was held by the ABS and the data collected on visa grants was administered by the former Department of Immigration and Citizenship (DIAC). In this paper, we examine the utility of these now linked administrative data sets on improving our knowledge about 
the timing and level of NOM propensities, or probabilities of 'NOM tagging' in the Australian migration system.

Specifically, we illustrate the use of the merged administrative data to answer three questions that investigate heterogeneity in 'NOMing'. First, with what propensity are people who were granted a particular visa type subsequently counted into or out of the Australian population, that is, they become a NOM Arrival or a NOM Departure? Second, how do NOM Arrival likelihoods vary by selected characteristics? Finally, what is the time distribution of being counted into and out of the Australian population relative to the time of the visa grant?

The structure of the remainder of this paper is as follows. Firstly, we provide a background on changes to NOM measurement in Australian and why the merging of these administrative data sets was required. Following this, we detail aspects of the data used to estimate the timing of NOM propensities. We then use these data to answer the three questions outlined above. We conclude with a discussion of our findings and the importance of further data linkages and improvements to NOM forecasting in Australia.

\section{Background on Measurement of Migration to Australia}

Changes in Australia's population result from the excess of birth over deaths (natural increase) and the excess of arrivals in the country over departures from the country (NOM). Until the early 1980 s, NOM was calculated as the excess of every arrival into the country (short-term, long-term or permanent) over every departure. The numbers coming into the country and the numbers going out were counted and their difference obtained. However, as the number of short-term movements across Australia's borders 
mushroomed, this approach was criticised because it meant that large numbers of people who are in the country for a very short period, such as tourists, were counted as part of the Australian population. It also meant that the population could fluctuate from quarter to quarter because the seasons for Australians to tour overseas and for overseas persons to tour in Australia differed. As the Estimated Resident Population is used as a component of the distribution of funds from the Australian Government to the State and Territory Governments, the inclusion of large numbers of short-term residents could not be tolerated

Thus, it was decided in the early 1980s that the Australian population should be defined as the total of persons who were usually resident in Australia, not simply as those that happened to be in Australia on any one day. Those arriving in the country were counted as usual residents if they intended to live in Australia for a continuous 12-month period (as declared on their Arrival Card). Those leaving Australia were counted out of the Australian usual resident population if they intended to stay away from Australia for a continuous period of more than 12 months (as declared on their Departure Card). The problem with this method was that people changed their intentions after they had completed their cards. Those who changed their intentions such that their movement shifted under or over 12 months were termed 'Category Jumpers'. To overcome this problem, the Australian Bureau of Statistics developed a method to adjust NOM using estimates of the numbers of category jumpers.

In the late 1990 s and early 2000 s, changes in immigration regulations particularly the issuance of visas onshore and an explosion in the numbers of long-term temporary movements in and out of Australia led to the collapse of the 'category jumping' 
approach that had been used since the early 1980s. For a period of four years from 1997-98 to 2000-01, the Australian Bureau of Statistics did not estimate the level of category jumping, effectively assuming that its value was zero. The published ABS estimates of annual net overseas migration rose in these years from 79,000 in 1997-98 to 136,000 in 2000-01. McDonald et al (2003) argued that net migration in these years had been overestimated because the nature of the new temporary flows was such that category jumping had become systematically negative and large. This was proven to be the case after ABS resumed its calculation of category jumping from 2001-02 to 200506. The total of category jumping across this five-year period was a negative 232,000. This implies that if category jumping had continued to be assumed to be zero, Australia's population would have been overestimated by this amount. However, because category jumping had become a very large negative number relative to the actual level of NOM, this called into question the method that ABS was using to estimate NOM. A more robust approach was required.

As a consequence, in 2006, the Australian Bureau of Statistics introduced a new definition of a usual resident of Australia. Under the new definition, a person is a usual resident of Australia if he or she spends at least 12 months of any given 16-month period in Australia. This is ascertained through matching of individual records for persons moving across Australia's borders, including their Arrival and Departure Cards, their passport movements and their visa grants. For example, a person may have entered Australia on 1 January 2006. If, by 31 April 2007, that person had an accumulated time in Australia of 12 months or more, even if they had left temporarily, they would be counted into the Australian population at 1 January 2006. Likewise, a person who left Australia on 1 January 2006 and, by 31 April 2007, had not accumulated 12 out of the 
ensuing 16 months in Australia would be counted out of the Australian population at 1 January 2006. The total number of persons counted into the population through arrival is termed NOM Arrivals. The total number of persons counted out of the population through departure is termed NOM Departures. The net of the two numbers is NOM or Net Overseas Migration. Calculations of NOM are made on a quarterly basis.

The main effect of the change in definition has been the inclusion of many temporary residents into the Australian Resident Population who would not previously have been counted as Australian residents even though they were in Australia most of the time. The two categories most concerned were international students and Long-Stay Business (457) visa holders. For two years, NOM was published using both the old (category jumping) method and the new (12/16) method. In 2004-05, NOM using the new method was 19,000 higher than by using the old method and in $2005-06$, it was 24,000 higher (Table 1).

\section{[TABLE 1]}

The data in Table 2 indicate that the large increase in NOM that occurred from 200405 to 2008-09 was associated with the very large increase in arrivals of long-term temporary immigrants, many of whom would not have been counted into the Australian population using the pre-June 2006 definition. From 2004-05 to 2008-09, the increase in net migration of permanent settlers was 15,000 while the increase in net migration of long-term temporary immigrants was 107,000. Table 3 shows the dominance of international students in the temporary migration gain. Many international students in Australia for more than one year return home in the teaching break at the end of the 
year and would not have been counted in the Australian population using the pre-June 2006 definition because they did not spend a continuous 12-month period in Australia.

\section{[TABLE $2 \&$ TABLE 3]}

\section{Methods}

\section{Data}

Given the knowledge that, since 2006, net overseas migration has been affected by new forces, especially temporary long-term arrivals, the proposal was made that it is in Australia's interest to have a better understanding of the movement processes that lead to people being counted in and out of the population under the new definition. Prior to 2009, the individual-level data on NOM tagging, that is, administrative data which tags individuals as belonging to the Australian population under the 12/16 rule, were held by the Australian Bureau of Statistics. In contrast, the data on individual visa grants were held by DIAC.

The database used to estimate the parameters for this study resulted from a matching of the ABS NOM database with databases on visa grants held by DIAC using a personal identifier number that was common to these databases. As the new method of estimating NOM has only been applied from the December quarter of 2003, the data that we used to estimate the propensities commence with visa grants in that quarter. The database used ends in mid 2009, the last quarter for which data were available from the ABS at the time of the study. Thus, after the databases were merged, we were able to trace individuals issued with a visa from 1 October 2003 until 2009 to see if that 
individual was subsequently included in the Australian population and in what quarter this occurred. In simple terms, this is the basis of our analyses. However, there are many complications given the relatively short-run nature of the data:

- Some people are issued with more than one offshore visa during this time period. Which visa grant should be used in the analysis?

- Some people issued with a visa after 1 October 2003 were also issued with a visa before 1 October 2003. They are often counted as a NOM arrival on the basis of the arrival in Australia relating to the earlier visa grant.

- After a visa is granted to a person who is overseas at the time, the person has a given amount of time in which they must arrive in Australia. For many visa categories, this period is as long as 12 months. After they arrive, their NOM status is based upon their calculated time in Australia in the subsequent 16month period. This means there can be a delay of 28 months following the grant of a visa before it becomes evident whether the grant has led to a person being counted as a NOM Arrival. If the person leaves Australia temporarily during the 16-month period after they arrived in Australia on the visa grant, then more months can potentially be added to the time required to see if the original arrival should be included as a NOM Arrival. It is possible, though rare, for a person to enter Australia on a particular visa type and then not be counted into the population for many years because, in each 16-month period they are out of Australia for more than four months. Because grants and movements are highly seasonal, at least a full 12 months of grants must be used to calculate the proportion of grants of a particular type that lead to a NOM Arrival. 
There are 22 quarters for which data were available to NOM tag the individuals. For the vast majority of people, this period is sufficiently long to observe whether or not an original visa grant leads to a NOM Arrival.

The basis of the calculations herein is visas granted offshore to citizens of countries other than Australia and New Zealand. The logic is that it is this offshore visa grant that brings the person to Australia in the first instance so it is the beginning of the process that leads to the person being counted or not counted as an Australian resident. In many cases, however, it is the subsequent granting of a visa onshore that enables an extension of time in Australia and enumeration in the Australian population. The calculations do not identify the effects of onshore visa grants. Also, it is possible that a person may visit Australia on a short visit (on a Visitor Visa) and then later obtain a long-stay visa. For example, a person coming on a Long-stay Business Visa might enter Australia as a tourist in one quarter, make arrangements for accommodation and schooling for their children, leave and then return to Australia in the next quarter after the Long-stay Business Visa is issued. We adopted two approaches to deal with a situation where there was more than one offshore visa grant in the person's record: the last visa method and the weighted visa method. The last visa method bases the calculations on the last (most recent) visa that the person was issued. The weighted method splits the results across the offshore visas that were granted. For example, if a person who was later included as a NOM Arrival had two visa grants, Type 1 and Type 2, each grant would be allocated half a NOM Arrival. For simplicity, in the following analyses, we present results using the last grant method. While there were some differences in propensities according to which method was used, the differences were small and often negligible because most people did not have multiple visas in their records. 


\section{Estimating NOM Timing Profiles}

With estimates of the NOM propensity (either based on the last or weighted method), the next step was to estimate the flow of individuals into the population via NOM (In or Out) that is attributable to different visa types over time. Using measure of the dates of visa grants and dates of NOM tagging, we estimated decay curves of the underlying propensities starting from the first and each subsequent quarter of grants. For the subsequent quarters we adjusted for censoring by using a contiguous imputation approach. Estimated decay curves for each grant time period were then averaged within each aggregate visa grant type and adjusted to ensure that the average concorded to the estimated propensity for each type.

To briefly illustrate this approach, results in Figure 2 show the timing of NOM out and NOM in for all visa types over 22 quarters. The broken line shows the completed propensity from the first period of grants followed across all 22 quarters. The grey line shows the NOM timing distributions averaged across all estimated distributions from the last quarter of 2003 onwards. The black line simply reweights the average distribution back to the estimated underlying propensity. As can be seen, the adjustment required is minimal.

\section{[FIGURE 2]}


As part of the project for DIAC completed in 2009 and again in 2011, calculations of propensities were performed at the visa sub-class level. Because the number of visas issued in some visa classes within a 12 -month period is very small, it was not possible to base the analysis upon all visa sub-class categories. Instead, sub-classes were aggregated into 23 categories and the analysis was conducted for these 23 categories. The concordance between individual visa categories and the 23 aggregated visa groups is shown in Appendix 1.

\section{Results}

What proportions of a visa category become a NOM Arrival and a NOM Departure?

Table 4 shows the propensity of each aggregated visa grant category to be counted into NOM Arrivals (counted into the Australian Resident Population) and NOM Departures (counted out of the Australian Resident Population) accumulated over 22 quarters of experience from the quarter that the grant was made.

Not unexpectedly, the highest propensity IN applied to Refugees at 98 per cent. This means that only two per cent of those granted a visa as a refugee were not counted into the Australian population at some time in the following 22 quarters. Also, only one per cent of the original entry of refugees was later counted out of the population. The Humanitarian movement was the only other movement with an IN propensity above 90 per cent and, again, a very low rate of subsequently leaving Australia. The propensities for other aggregated categories can be read from the table. 


\section{[TABLE 4]}

Among the permanent skilled entry categories, the highest IN propensity applies to the Employer Sponsored group at 81 per cent. This is to be expected as these people are granted their visa on the basis that they have a job to come to in Australia, or that they are already employed in Australia on a temporary visa. However, they were more likely to later leave Australia than other Skilled Categories. Some of the Skilled categories have surprisingly low propensities. For example, the propensity to be counted into the Australian population was only 65 per cent for the Skilled Independent category. Most of these people probably entered Australia but left again having taken up their permanent residence. For the Business Skills group, only a bare majority (51 per cent) stayed in Australia for the period required to be counted into the population and, in net terms, only 47 per cent remained in Australia. The intake for these various skilled permanent categories is based upon a careful assessment of labour force shortages in Australia. More points are awarded for those skills (occupations) adjudged to be most in demand. The fact that such high percentages of these people - so carefully selected eventually do not stay in Australia long enough to be counted into the population is a matter for policy consideration. Also, it is this group of skilled permanent entrants who are the popular conception of 'Australian immigrants'. When Australians call for migration to be cut or to be increased, it is this group that they have in mind. Thus, their relatively low take-up of Australian residence needs to be considered if any cut or any increase is being considered.

The IN propensity for 457 visa grantees was 66 per cent while the OUT percentage was 13 per cent. The grant of a visa in these cases is based upon a pre-existing offer of 
employment is Australia. Grants in this category can be for periods as short as six months and this may be a reason that 34 per cent do not count into the Australian population. Some others may spend long periods outside of Australia and never manage to accumulate 12 months residence in a 16 -month period.

Among the student categories, the IN propensity to add to the Australian population is highest for the higher education students (78 per cent), still relatively high for the VET students (75 per cent) but relatively low (37 per cent) for Students - Other who are mainly students taking short-term courses of less than 12 months (ELICOS, nonaward). However, the Student - Other category also includes those attending primary or secondary school in Australia. Higher education students have the highest NOM OUT propensity of any category in Table 4.

The propensity to be counted into the population is understandably high for partners and preferential/other family, but not as high as might be expected for parents. Only 15 per cent of Working Holiday Makers stay sufficiently long in Australia to be counted into the population and half of them are counted out. Among Visitors (effectively tourists and business short-stay visa holders), the propensities to be included in the Australian population are small but, because these movements are very large, even a small propensity converts into large numbers.

The NOM IN and NOM OUT percentages for Australian and New Zealand citizens are shown in Table 5. The important conclusion to be drawn from the table is that there are trends in the data across time. The net loss of Australians falls considerably across the years, 2004 to 2008 while the net gain of New Zealanders increases. While once it was 
possible to assume as a rough rule of thumb that the overall loss of Australians to any country balanced the gain of New Zealanders, this became increasingly less the case in this period with Australia experiencing a net gain across these two categories combined. For these two categories, the important consideration is understanding the future drivers of the trend. This is mainly a function of the state of the Australian economy relative to that of the New Zealand economy and the economies in countries such as the United Kingdom and the United States.

\section{[TABLE 5]}

What is the variation by selected characteristics?

A further use of the administrative data is to understand variations in propensities by characteristics such as sex, age and citizenship. In further analyses (omitted here), propensities for the 23 visa groups were examined by age and sex for all 23 visa groups. The general tendency from these results was that the propensity to NOM IN falls as age increases. However, this was not the case for general skilled migration (GSM) Australian Sponsored and GSM State and Territory Sponsored where the rates did not fall as age increased. The exceptional case was the Contributing Parent category where the propensity to NOM IN increased with age. Working Holiday Makers were also more likely to NOM IN as age increased.

Differences in NOM IN propensities by sex were very small for all visa categories except students for whom men had higher percentages than women and the small Business Skills category for whom women had higher percentages than men. 
Patterns by country of citizenship are less easy to see because of the large number of countries considered. Among the various skilled categories, NOM IN propensities tended to be high for all visa categories for citizens of the United Kingdom, Ireland, South Africa, India, Netherlands and Germany. The propensities tended to be on the low side for citizens of South East Asian and East Asian countries, and for the United States. As an exception to this last statement, the propensities were relatively high for the Skilled Independent category for citizens from China and Korea (Table 6).

\section{[TABLE 6]}

For students, the NOM IN propensities varied very widely across countries of citizenship. For all three categories of students, the NOM IN percentages were exceptionally high for those from China and India, moderately high for those from South East Asian countries and low for those from European countries, the USA and Canada. For Long-Stay Business visa holders (457), the NOM IN propensities were highest for South Africa, China and the United Kingdom and were moderately high for those from South East Asia and Japan. For Partners, the NOM IN propensities are highest for those from Ireland, the United Kingdom and Ireland. For Parents, NOM IN percentages are highest for China, Thailand, USA and India.

What is the time distribution of being counted into and out of the Australian population relative to the time of the visa grant? 
For all those eventually counted into the Australian population, the following set of charts (Box 1) shows for selected aggregated visa category the distribution of the quarters in which persons were included in the Australian population relative to the quarter in which the visa grant was made. ${ }^{2}$ The charts also show the time distributions for those counted out of the Australian population. Summing across all points on the line for NOM IN and NOM Out will yield the propensities presented earlier in Table 4. For example, for All visa categories combined the total NOM IN propensity was 0.07 . As shown in Box 1, the majority of additions to the population through NOMing is in the first 2 quarters following the visa issue. For the employer Sponsored Skilled category (with a NOM in propensity of 0.81 ), about 0.31 were counted into the population in the first quarter and 0.35 in the second quarter. This is one of the fastest rates of inclusion in the Australian population subsequent to a visa grant. In contrast, the speed is much slower for the Business Skills category and for the Skilled Independent category. A high proportion of refugee and humanitarian immigrants arrive in the quarter following the grant of the visa and a high percentage of students arrive in the quarter in which the visa is granted. The arrival times for Skilled Independent and for Business Skills are more widely spread than for any other category of arrival.

The charts show that, by the $22^{\text {nd }}$ quarter, the incidence of NOM IN is close to zero, confirming the method that has been applied to estimate the eventual propensities shown in Table 4. This is not the case for the NOM OUT calculation where rates are still greater than zero in most cases at the end of the 22 quarters. The decay in the NOM

\footnotetext{
${ }^{2}$ Note, in cases where the person was determined to be a NOM Arrival on the basis of a visa grant prior to the last visa grant, he/she is counted in the same quarter in which the last visa was granted.
} 
OUT duration is a function of the duration of the visa type under consideration and it tends to be longer for the permanent residence categories.

\section{Discussion}

The purpose of this study has been to illustrate the use of linked administrative data to understand heterogeneity in NOM propensities, and variations that can be observed by visa class and overtime.

Approaches to NOM estimation and NOM forecasting that incorporate the kinds of heterogeneity that we observed are likely to improve accuracy of standard methods based on aggregate data. Some studies have shown the projections of NOM produced by the Australian Bureau of Statistics to be 'highly inaccurate' (Wilson, 2017; Wilson, 2012; CEPAR 2017). In a recent paper, Wilson (2017) offers a pathway forward to improve NOM projections. Firstly, and of importance, the use of data on visa and citizenship category are seen as key to improving Australian NOM projections. Indeed, as shown in this paper, there is considerable variability in the level and timing of NOM propensities by visa class. Given the use of the 12/16 rule to measure NOM, we would contend that central to any forecasting model would be a determination of the timing of propensities. Wilson (2017) further suggests a 'combined migration forecasting approach' which draws together a number of strategies, dependent on the time frame of the projection. These include analyses of the direction and level of net flows, based on (1.) expert based analyses, (2.) explanatory models (3.) use of leading indicators and (4.) long-run trend analyses of immigration, emigration and NOM. With the availability 
of unit record administrative data, there is also the potential for a more nuanced and detailed econometric models of NOM event histories.

Recently, the Department of Immigration and Border Protection have implemented a new methodology for short term projections of NOM (DIBP, 2016). Although the published detail of this model is limited, they note that projections are conducted at a visa class level, and combined with forecasts of NOM propensities, visa grants, unemployment levels and other criteria (see Appendix B - DIBP, 2016). The new model specifically relies upon "which data source is the best predictor of NOM for the major visa category in question" (DIBP, 2016: 16). With model projections to 2020, evaluations of the forecast accuracy like that conducted by Wilson (2017) are a priority.

A further implication of our analyses is that administrative data, although with its limitations, can answer many questions that may not be readily available through other collection methods such as sample survey data sets. There are several obvious extensions to the analyses herein. Firstly, with a much longer run of visa grant and NOM data, it would be fruitful to examine the tails of the NOM IN and NOM OUT distributions by visa class. That is, how the NOM IN and NOM OUT processes unfold over time. A second extension would be to consider the utility of linking these data to other government collections. Obviously, this carries the inherent constraint of privacy concerns and data sovereignty. Noting this concern, a probabilistic match between these data and, for example, Centrelink or Department of Health administrative data sets could inform policy makers of the use of government programs on health and social welfare by recently arrived migrants. Linking the migration data to Australian Tax Office data could improve our understanding of the economic benefits of migration to 
Australia. With appropriate policies and procedures in place, there is a considerable case based on the 'public good' to link these data sets.

In interpreting these results, it is important to recognize the study's limitations. Since these data were made available to the authors, a number of improvements to the measurement of NOM have been made using the administrative data. The IT system for collecting the Overseas Arrivals and Departures data was rebuilt and a new imputation system for missing records was implemented (utilizing hot-decking). The ABS notes that this rebuild has improved the quality of NOM estimates, particularly between preliminary and final estimates (ABS, 2013). With these improved processes in place, and further years of data available, a priority should be to revisit alternative approaches to forecasting NOM in Australia and to evaluate government forecasts when they become available..

\section{Conflict of Interest}

None.

\section{Acknowledgement}

Data for this study were made available to the authors by the former Department of Immigration and Citizenship. Author 1 is funded by the Australian Research Council's Centre of Excellence in Population Ageing Research (CE1101029). The opinions expressed herein are those of the authors alone. 


\section{References}

ABS. (2017). Migration, Australia 2015-16. Catalogue number 3412.0, Australian Bureau of Statistics: Canberra.

CEPAR. (2017). A Visual History of Demographic Projections in Australia. ARC Centre of Excellence in Population Ageing Research: Sydney. Available from: http://www.cepar.edu.au/sites/default/files/A_Visual_History_of_Demographic_Proje ctions_in_Australia.pdf

Cully, M., Pejoski, L. (2012). Australia unbound? Migration, openness and population futures, pp. 60-71. In Pincus, J and Hugo, G (eds) A greater Australia: Population, policies and governance. CEDA: Melbourne.

DIBP. (2016). The Outlook for Net Overseas Migration, As at September 2016. Department of Immigration and Border Protection: Canberra.

McDonald, P., Khoo, S-E., Kippen, R. (2003). Alternative net migration estimates for Australia: Exploding the myth of a rapid increase in numbers. People and Place 11(3): 23-36.

McDonald, P. (2015). 'International migration and employment in Australia'. Population Review. 54(2): 1-12. 
Wilson, T. (2017). Can international migration forecasting be improved? The case of Australia. Migration Letters 14(2): 285-299.

Wilson, T. (2012). Forecast Accuracy and Uncertainty of Australian Bureau of Statistics State and Territory Population Projections. International Journal of Population Research. 


\section{University Library}

\section{- $\mathrm{M}$ IIN E R VA A gateway to Melbourne's research publications}

Minerva Access is the Institutional Repository of The University of Melbourne

Author/s:

Temple, JB;McDonald, PF

Title:

Australian migration propensities by visa class: an analysis of linked administrative data

\section{Date:}

2018-12-01

Citation:

Temple, J. B. \& McDonald, P. F. (2018). Australian migration propensities by visa class: an analysis of linked administrative data. Journal of Population Research, 35 (4), pp.399-416. https://doi.org/10.1007/s12546-018-9211-1.

Persistent Link:

http://hdl.handle.net/11343/253839 